\title{
Management of acute severe ulcerative colitis (NICE CG 166)
}

\author{
Authors: Lucia Macken ${ }^{A}$ and Paul A Blaker ${ }^{B}$
}

Ulcerative colitis (UC) presents as an acute severe flare in $10-15 \%$ of new cases and it occurs in $15 \%$ of patients with established disease. Acute severe UC can lead to significant morbidity and mortality in predominantly younger patients without other comorbidities. Inpatient hospital admission and a multidisciplinary approach are vital in appropriate and timely management. Important but simple aspects in the initial work-up and treatment of such patients are frequently overlooked during the acute medical take. An overview of the general and more specialist management of this important presentation are discussed herein.

\section{Introduction}

Ulcerative colitis (UC) is a chronic inflammatory disease of the colon, characterised by continuous mucosal inflammation from the rectum through a variable length of the colon, which manifests as bloody diarrhoea with colicky abdominal pain and faecal urgency. The disease typically follows a relapsing-remitting course and usually presents in young adult life (15-30 years). The majority of affected patients present with mild-moderate disease, however $10-15 \%$ of patients have severe inflammation at diagnosis. Additionally, over the course of their lifetime, 15\% of affected patients will develop an acute severe flare requiring hospitalisation. ${ }^{1}$ Acute severe UC (ASUC) is defined as the passage of six or more loose stools, with blood, per day with evidence of systemic toxicity (Table 1). This is a medical emergency and is associated with a mortality of up to $2.9 \%$ in peripheral centres and $<1 \%$ in specialist inflammatory bowel disease (IBD) units. Therefore, prompt recognition and appropriate intervention are crucial to reduce morbidity and mortality.

\section{Diagnosis}

The diagnosis of UC is established by finding characteristic intestinal ulceration and excluding alternative diagnoses, most importantly infectious colitis (IC) (Table 2). History taking should focus on the onset and chronicity of symptoms, stool frequency and consistency, the presence or absence of blood, abdominal pain and nocturnal symptoms. Systems review should determine constitutional symptoms including fever,

Authors: ${ }^{\text {A }}$ specialist registrar in gastroenterology, Tunbridge Wells Hospital at Pembury, Pembury, UK; ${ }^{B}$ consultant in gastroenterology, Tunbridge Wells Hospital at Pembury, Pembury, UK weight loss and malaise, and the presence or absence of extraintestinal manifestations of IBD. Recent use of non-steroidal anti-inflammatory drugs (NSAIDs) or antibiotics may suggest a drug-induced colitis or highlight a risk of Clostridium difficile infection. Smoking behavior appears protective against UC, whereas $5.5-17.5 \%$ of patients with UC have a first-degree relative with the condition. ${ }^{2}$ A sexual history should establish the risk of Chlamydia trachomatis infection, which can cause a proctitis. Finally, a travel history should explore the possibility of an endemic gastrointestinal infection. This is of critical importance in patients with amoebiasis or strongyloidiasis, in whom the use of corticosteroids for a presumed flare of UC could lead to a hyper-infection with significant mortality.

\section{Investigations}

Initial investigations should include a full blood count (FBC), blood group and antibody screen, inflammatory markers (specifically CRP), urea and electrolytes (U+Es) and liver function tests. At least three stool samples should be obtained for microscopy culture and sensitivity and testing for $C$ difficile antigen. Additional samples for ova, cysts and parasites

\section{Key points}

Patients with acute severe ulcerative colitis should be admitted to hospital for intensive treatment.

Patients with intestinal perforation, exsanguinating haemorrhage or toxic megacolon should be considered for immediate colectomy.

Initial medical management includes intravenous corticosteroids, venous thromboembolism prophylaxis, oral or enteral feeding as tolerated, and exclusion of infection including Clostridium difficle.

Failure of initial medical management by day 3 of corticosteroids should prompt escalation to rescue therapy with either ciclosporin or infliximab, or referral for colectomy.

Colectomy should be considered for patients who do not respond to rescue therapy within 7 days of their initiation.

KEYWORDS: Ulcerative colitis, severe, ciclosporin, infliximab, colectomy 
Table 1. Classification of disease severity in ulcerative colitis. Adapted from Truelove and Witts' criteria.

\begin{tabular}{ll} 
Disease severity & Characteristics \\
Mild & $<4$ stools/day $+/$ - blood, normal ESR, no \\
& signs of toxicity \\
& $4-6$ stools/day, occasional blood, minimal \\
Moderate & signs of toxicity, CRP $\leq 30 \mathrm{mg} / \mathrm{L}$ \\
& $\geq 6$ bloody stools/day AND any of: \\
Severe & $>$ temperature $>37.8^{\circ} \mathrm{C}$ \\
& $>$ tachycardia $>90 \mathrm{bpm}$ \\
& $>$ anaemia, $\mathrm{Hb}<105 \mathrm{~g} / \mathrm{L}$ \\
& $>$ ESR $>30 \mathrm{~mm} / \mathrm{h}, \mathrm{CRP}>30$ mg/L \\
& 10 stools/day, continuous bleeding, toxicity, \\
& abdominal tenderness or distention, \\
& transfusion requirement, colonic dilatation \\
Fulminant & on $\mathrm{X}$-ray \\
\hline CRP $=$ C-reative protein; & ESR $=$ erythrocyte sedimentation rate; $\mathrm{Hb}=$ \\
haemoglobin. &
\end{tabular}

should be obtained if there is a relevant travel history. A plain abdominal X-ray (AXR) should be performed and examined for the presence of mucosal islands, colonic dilatation $(\geq 5.5 \mathrm{~cm})$, distended loops of small bowel gas $(\geq 3)$, or perforation. ${ }^{3}$ Additional tests may include a pregnancy test (if appropriate) and a pre-immunosuppression screen (chest X-ray, tuberculosis interferon- $\gamma$ release assay, hepatitis B surface antigen and core antibody, hepatitis C antibody, HIV and varicella serology) in case rescue therapy with ciclosporin or infliximab is required. An unprepared flexible sigmoidoscopy by an expert endoscopist may assist in the diagnosis and staging of disease but it should not delay the initial management. Colonic biopsies should be obtained in immunosuppressed patients to exclude cytomegalovirus infection.

Table 2. Important differentials in the diagnosis of ulcerative colitis.

$\begin{array}{ll}\text { Diagnosis } & \text { Differentials } \\ \text { Infectious colitis } & >\text { Campylobacter spp } \\ & >\text { Salmonella } \\ & >\text { Escherichia coli } 0157 \\ & >\text { Shigella } \\ & >\text { Clostridium difficile } \\ & >\text { Cytomegalovirus-induced colitis in } \\ & \text { immunosuppressed patients } \\ & >\text { Chlamydia trachomatis } \\ & \text { (lymphogranuloma venereum) } \\ & >\text { Crohn's disease } \\ \text { Inflammatory } & \text { Diverticulitis } \\ \text { Vascular } & >\text { Ischaemic colitis } \\ \text { Iatrogenic } & >\text { Drug-induced colitis, particularly non- } \\ & \text { steroidal anti-inflammatory drugs } \\ & \text { Radiation protopathy }\end{array}$

Distinguishing between UC and IC can be challenging, however pyrexia $>38.5^{\circ} \mathrm{C}$ is only seen in approximately $10 \%$ of patients with UC; colicky abdominal pain is more common in IC; the white blood cell count tends to be higher in UC than IC; the CRP is often higher in IC; thrombocytosis is more common in UC as compared to IC. ${ }^{4}$

\section{Medical management}

Patients with ASUC should be admitted to hospital under a gastroenterology team and reviewed on a daily basis by a consultant gastroenterologist in close liaison with a colorectal surgeon (Fig 1). The cornerstone of management for ASUC remains the use of intravenous corticosteroids, which are effective in the induction of remission in the majority (70\%) of cases. ${ }^{5}$ A bolus regimen of intravenous hydrocortisone $100 \mathrm{mg}$ four times daily is recommended and should be administered before the results of stool microbiology are available, unless there is a high suspicion of amoebiasis or strongyloides infection.

Thromboprophylaxis against venous thromboembolism should be prescribed in all cases. Fluid status should be assessed and intravenous fluids prescribed to correct hypovolaemia. Hypokalaemia and hypomagnaesemia should be corrected to reduce the risk of colonic dilatation. Potassium requirements are typically $>60 \mathrm{mmol} /$ day to account for stool loss and the effects of hydrocortisone. Bowel rest has not been shown to improve outcomes, however enteral nutrition should be considered for severely malnourished patients. Any medications that can precipitate colonic dilatation, including opiates, NSAIDs, anti-cholinergics and anti-diarrhoeals, should be withheld. The routine use of intravenous antibiotics in patients with uncomplicated ASUC is not recommended, although it may be appropriate when incipient colonic perforation, toxic dilatation or infection is suspected. ${ }^{6}$ Furthermore, there is no evidence confirming the benefit of 5-aminosalicylate (5-ASA) drugs in ASUC. Indeed, treatment with these agents should be avoided during an acute severe flare, owing to the risk (3\%) of a paradoxical response. ${ }^{1}$

Stool frequency has been validated as a clinical marker of response to therapy and predicts the need for rescue therapy. ${ }^{3}$ The importance of an accurate stool chart should be discussed with the patient and they should be encouraged to complete it themselves. In this regard, a 'bowel movement' describes an episode of passing a liquid or formed stool which is considered 'complete' once the patient leaves the bathroom.

\section{Assessing response to medical treatment}

The FBC, U+Es, albumin, CRP and stool frequency should be checked on a daily basis. The AXR should be repeated daily if there is severe extensive colitis, dilatation on the previous AXR, fever, tachycardia or abdominal tenderness; otherwise repeating it every other day will suffice. In patients without evidence of toxic dilatation and impending perforation, a decision to continue with standard therapy, to commence rescue therapy, or to proceed to a colectomy should be made by the consultant gastroenterologist in conjunction with a colorectal surgeon at the end of 72 hours of intravenous hydrocortisone. In patients who respond to standard therapy, intravenous hydrocortisone should be continued for a minimum of five days before 


\begin{tabular}{|c|c|c|c|}
\hline \multicolumn{3}{|c|}{ Day 0} & \multirow{2}{*}{ General management throughout } \\
\hline$\downarrow$ & $\downarrow$ & 7 & \\
\hline $\begin{array}{l}\text { Initial workup } \\
\text { - FBC, U\&E, LFT, CRP, G\&S } \\
\text { - stool cultures: MC\&S and CDT } \\
\text { - AXR } \\
\text { - stool chart }\end{array}$ & $\begin{array}{l}\text { Initial treatment } \\
\text { - IV hydrocortisone } 100 \text { mg qds } \\
\text { - prophylactic low molecular } \\
\text { weight heparin s/c } \\
\text { - IV fluids, consider potassium } \\
\text { replacement } \\
\text { - stop antidiarrhoeals and } \\
\text { anticholinergics }\end{array}$ & $\begin{array}{l}\text { Further work-up } \\
\text { - gastroenterology review } \\
\text { - flexible sigmoidoscopy and } \\
\text { biopsy } \\
\text { - consider surgical review }\end{array}$ & $\begin{array}{l}\text { - Bloods } \\
\text { > U\&Es } \\
\text { > CRP } \\
\text { > FBC } \\
\text { - Observation chart } \\
\text { > temperature } \\
\text { > heart rate } \\
\text { > stool chart }\end{array}$ \\
\hline \multicolumn{3}{|c|}{ Day 3} & \multirow{4}{*}{$\begin{array}{l}\text { - Abdominal examination } \\
\text { - Early consideration of rescue } \\
\text { therapy } \\
\text { > TPMT } \\
\text { > magnesium } \\
\text { > cholesterol } \\
\text { > hepatitis B and C serology } \\
\text { > tuberculosis screening } \\
\text { - chest X-ray } \\
\text { - interferon-gamma release } \\
\text { assay }\end{array}$} \\
\hline$\downarrow$ & $\downarrow$ & $\downarrow$ & \\
\hline $\begin{array}{l}\text { Reassess } \\
\text { - bloods, particularly CRP } \\
\text { - stool frequency } \\
\text { - microbiology results } \\
\text { - consider further AXR }\end{array}$ & $\begin{array}{l}\text { Identify high-risk patients } \\
\text { - stool frequency }>8 / \text { day } \\
\text { - CRP }>45 \mathrm{mg} / \mathrm{L} \\
\text { - require treatment escalation }\end{array}$ & $\begin{array}{l}\text { Management decisions } \\
\text { - continue hydrocortisone } \\
\text { - start rescue therapy } \\
\text { > ciclosporin } \\
\text { > infliximab } \\
\text { - consider surgery }\end{array}$ & \\
\hline \multicolumn{3}{|c|}{ Days 3-7 } & \\
\hline$\downarrow$ & 1 & 7 & \multirow[b]{2}{*}{$\begin{array}{l}\text { - Early input from multidisciplinary } \\
\text { team } \\
\text { > colorectal surgeon } \\
\text { > stoma nurse } \\
\text { > dietitian } \\
\text { - Consider cross-sectional imaging } \\
\text { if adverse features } \\
>C T \text { abdomen } \\
\text { Clinical conditition may deteriorate } \\
\text { at any point }\end{array}$} \\
\hline $\begin{array}{l}\text { IV hydrocortisone responder } \\
\text { - bloods, particularly CRP } \\
\text { - stool frequency } \\
\text { - convert to oral prednisolone } \\
>40 \mathrm{mg} \text { od, decrease by } \\
5 \mathrm{mg} / \text { week } \\
>\text { co-prescribe calcium and } \\
\text { vitamin D } \\
\text { - urgent r/v in gasto outpatients }\end{array}$ & $\begin{array}{l}\text { Rescue therapy responder } \\
\text { - ciclosporin } \\
\text { > convert to oral after } 5-7 \text { days } \\
\text { > bridge to thiopurine } \\
\text { - infliximab } \\
\text { > ween prednisolone } \\
\text { - co-trimoxazole } 480 \text { mg od } \\
\text { - assess on day } 7 \text { for response } \\
\text { > if not responded, likely } \\
\text { requires colectomy }\end{array}$ & $\begin{array}{l}\text { Rescue therapy non-responder } \\
\text { - surgery } \\
\text { > colorectal surgeon } \\
\text { > stoma nurse } \\
\text { > multidisciplinary input }\end{array}$ & \\
\hline
\end{tabular}

Fig 1. Management algorithm for acute severe colitis. $A X R=$ abdominal $X$-ray; $C D T=C l o s t r i d i u m$ difficile toxin; $C R P=C$-reactive protein; $C T=$ computerised tomography; FBC = full blood count; G\&S = group and save; IV = intravenous; LFT = liver function tests; $M C \& S=$ microscopy, culture and sensitivity; OD = once daily; $\mathrm{s} / \mathrm{C}=$ subcutaneous; TPMT = thiopurine methyltransferase; $U \& \mathrm{E}=$ urea and electrolytes.

switching to prednisolone $40 \mathrm{mg}$ daily, which can be tapered by $5 \mathrm{mg}$ every week provided the patient remains in remission. Furthermore, topical and/or oral 5-ASA therapy can be restarted or commenced once the patient is improving.

Approximately $30 \%$ of patients with ASUC demonstrate 'steroid refractory' disease, defined as a stool frequency $>8 /$ day or a stool frequency between 3-8 and a CRP $>45 \mathrm{mg} / \mathrm{L}$ after 72 hours of intravenous corticosteroids (Oxford criteria), which predicts an $85 \%$ likelihood of requiring a colectomy. ${ }^{3}$ This group of patients may benefit from second-line rescue therapy with either ciclosporin or infliximab (TNF- $\alpha$ antagonist). The National Institute for Health and Care Excellence (NICE) recommends the preferential use of ciclosporin ( $2 \mathrm{mg} / \mathrm{kg} /$ day $)$, with infliximab reserved for patients in whom calcineurin inhibitors are contraindicated or clinically inappropriate (eg uncontrolled hypertension, chronic kidney disease, previous non-response or intolerance to calcineurin inhibitors).

Early results from a randomised controlled trial comparing ciclosporin with infliximab suggest no significant differences in quality adjusted survival, colectomy rates, mortality and serious adverse reactions between the two treatments. ${ }^{7}$ The initial response rate to ciclosporin reported in clinical trials is $64-86 \%$, however long-term outcomes are significantly poorer, with observational studies suggesting colectomy rates of 38$88 \%$ at up to seven years in initial responders..$^{8-13}$ In patients who respond to intravenous ciclosporin, therapy is transitioned to oral ciclosporin ( $5 \mathrm{mg} / \mathrm{kg}$ ) after 5-7 days. A thiopurine can be started concurrently with oral ciclosporin, with the aim of discontinuing ciclosporin by 3-6 months. In patients receiving triple immunosuppression with corticosteroids, a thiopurine, and ciclosporin or infliximab, Pneumocystis jirovecii prophylaxis with co-trimoxazole (480 mg daily or $960 \mathrm{mg}$ every other day) is recommended. ${ }^{14}$

Standard induction therapy with infliximab $(5 \mathrm{mg} / \mathrm{kg})$ is given at weeks 0,2 and 6 . However in ASUC, an accelerated regimen of infliximab may be more effective. In patients given three doses of infliximab within a median of 24 days as compared to standard induction therapy, the three-month colectomy rates were significantly lower in the accelerated treatment group. ${ }^{15}$ This strategy is yet to be recommended by NICE. Similarly, concomitant initiation of a thiopurine with infliximab has not been specifically studied in ASUC; however this strategy improves the rate of corticosteroid-free remission and mucosal healing in patients with moderate to severe UC. ${ }^{16}$

\section{Surgical management of acute severe UC}

Colectomy should be considered early in the management of ASUC in patients with intestinal perforation, exsanguinating haemorrhage or toxic megacolon. Otherwise a colectomy should be considered after three days of hospitalisation in patients with steroid refractory disease deemed inappropriate 
for second-line therapy, or where there has been no improvement within seven days after the introduction of rescue therapy. Planned colectomy is associated with significantly improved morbidity and mortality rates in comparison with urgent colectomy, which highlights the importance of promptly identifying patients likely to require surgical intervention. ${ }^{17}$ Colectomy with ileostomy is the preferred initial operation. A completion proctectomy with pouch can be planned at a later date, once the patient has improved physically and nutritionally.

\section{Conclusion}

The management of ASUC is challenging and necessitates collaborative working between gastroenterology and surgical teams. Early recognition of the diagnosis and initiation of treatment is essential, as is early evaluation of treatment response. The majority of patients will respond to either first- or second-line medical therapies; however colectomy can be lifesaving for some patients. Response to rescue therapies should be determined within seven days of their initiation, since prolonged medical treatment and hospitalisation are associated with poorer patient outcomes. Individualising the treatment strategy to each patient is essential to maximise the chance of a successful outcome.

\section{References}

1 Doherty GA, Cheifetz AS. Management of acute severe ulcerative colitis. Expert Rev Gastroenterol Hepatol 2009;3:395-405.

2 Monsen U, Brostrom O, Nordenvall B, Sorstad J, Hellers G. Prevalence of inflammatory bowel disease among relatives of patients with ulcerative colitis. Scand J Gastroenterol 1987;22:214-8.

3 Travis SP, Farrant JM, Ricketts C et al. Predicting outcome in severe ulcerative colitis. Gut 1996;38:905-10.

4 Mantzaris GJ, Hatzis A, Archavlis E et al. The role of colonoscopy in the differential diagnosis of acute, severe hemorrhagic colitis. Endoscopy 1995;27:645-53.

5 Mowat C, Cole A, Windsor A et al. Guidelines for the management of inflammatory bowel disease in adults. Gut 2011;60:571-607.

6 Mantzaris GJ, Petraki K, Archavlis E et al. A prospective randomized controlled trial of intravenous ciprofloxacin as an adjunct to corticosteroids in acute, severe ulcerative colitis. Scand J Gastroenterol 2001;36:971-4.
7 Williams J, Alam MF, Alrubaiy L et al (eds). Comparative clinical effectiveness of infliximab and ciclosporin for acute severe ulcerative colitis: early results from the CONSTRUCT trial. Vienna: UEGW, 2014.

8 Lichtiger S, Present DH, Kornbluth A et al. Cyclosporine in severe ulcerative colitis refractory to steroid therapy. $N$ Engl J Med 1994;330:1841-5.

9 Van Assche G, D’Haens G, Noman M et al. Randomized, double-blind comparison of $4 \mathrm{mg} / \mathrm{kg}$ versus $2 \mathrm{mg} / \mathrm{kg}$ intravenous cyclosporine in severe ulcerative colitis. Gastroenterology 2003;125:1025-31.

10 D'Haens G, Lemmens L, Geboes K et al. Intravenous cyclosporine versus intravenous corticosteroids as single therapy for severe attacks of ulcerative colitis. Gastroenterology 2001;120:1323-9.

11 Cohen RD, Brodsky AL, Hanauer SB. A comparison of the quality of life in patients with severe ulcerative colitis after total colectomy versus medical treatment with intravenous cyclosporin. Inflamm Bowel Dis 1999;5:1-10.

12 Campbell S, Travis S, Jewell D. Ciclosporin use in acute ulcerative colitis: a long-term experience. Eur J Gastroenterol Hepatol 2005; 17:79-84.

13 Moskovitz DN, Van Assche G, Maenhout B et al. Incidence of colectomy during long-term follow-up after cyclosporine-induced remission of severe ulcerative colitis. Clin Gastroenterol Hepatol 2006;4:760-5.

14 Rahier JF, Ben-Horin S, Chowers Y et al. European evidencebased consensus on the prevention, diagnosis and management of opportunistic infections in inflammatory bowel disease. J Crohns Colitis 2009;3:47-91

15 Gibson DJ, Heetun ZS, Redmond CE et al. An accelerated infliximab induction regimen reduces the need for early colectomy in patients with acute severe ulcerative colitis. Clin Gastroenterol Hepatol 2015;13:330-5.e1.

16 Panaccione R, Ghosh S, Middleton S et al. Combination therapy with infliximab and azathioprine is superior to monotherapy with either agent in ulcerative colitis. Gastroenterology 2014;146:392-400.e3.

17 Teeuwen PH, Stommel MW, Bremers AJ et al. Colectomy in patients with acute colitis: a systematic review. J Gastrointest Surg 2009;13:676-86.

Address for correspondence: Dr PA Blaker, Tunbridge Wells Hospital at Pembury, Tonbridge Road, Pembury TN2 4QJ, UK. Email: paul.blaker@nhs.net 